\title{
Effect of Elaeagnus Conferta Roxb (Elaeagnaceae) Dry Fruit on the Activities of Hepatic Alcohol Dehydro- genase and Aldehyde Dehydrogenase in Mice
}

\author{
Chongming $\mathrm{Wu}^{1}$, Rongji Dai ${ }^{1,2}$, Jingmiao Bai ${ }^{1}$, Yan Chen ${ }^{1,2}$, Yuhong $\mathrm{Yu}^{1,2}$, \\ Weiwei Meng ${ }^{1,2^{*}}$ and Yulin Deng ${ }^{1,2}$ \\ ${ }^{1}$ School of Life Science, Beijing Institute of Technology, Beijing 100081, ${ }^{2}$ GY Pharmaceutical R\&D, Beijing 100081, \\ PR China
}

\begin{abstract}
Purposes: To determine the effect of Elaeagnus conferta Roxb dry fruit powder (ECR) on blood alcohol clearance and on the activities of hepatic alcohol dehydrogenase (ADH) and aldehyde dehydrogenase $(\mathrm{ALDH})$.

Methods: In a randomized controlled study, acute alcohol intoxication was induced in mice with Hongxing liquor containing $65 \% \mathrm{v} / \mathrm{v}$ ethanol orally. The effect of ECR on blood alcohol clearance and on the activities of hepatic alcohol dehydrogenase and aldehyde dehydrogenase in the mice was then investigated.

Results: A 30-min pretreatment with ECR at 400 and $800 \mathrm{mg} / \mathrm{kg}$ led to a faster clearance of blood alcohol after the alcohol ingestion. The concentration of blood alcohol at $4 \mathrm{~h}$ after alcohol ingestion decreased by $21.2 \%$ in mice pretreated with $800 \mathrm{mg} / \mathrm{kg}$ ECR. The activities of hepatic alcohol dehydrogenase (ADH) and aldehyde dehydrogenase (ALDH) were enhanced by ECR.

Conclusion: These results suggest that pretreatment with ECR might stimulate the clearance of blood alcohol by increasing the activities of hepatic alcohol dehydrogenase and aldehyde dehydrogenase.
\end{abstract}

Keywords: Elaeagnus conferta Roxb, blood alcohol clearance, alcohol dehydrogenase (ADH), aldehyde dehydrogenase (ALDH). 


\section{INTRODUCTION}

Consumption of alcohol is rapidly increasing these days. However, heavy drinking does much harm to human health. Short-term toxic effects of alcohol include facial flushing, tachycardia, palpitation, confused consciousness, vomiting, etc. Long-term excessive alcohol use leads to cirrhosis [1], alcohol liver disease [2], pancreatitis [3], neurologic [4], gastrointestinal damages [5], osteoporosis [6] and others. Several efforts have been made to relief alcohol toxicity using synthetic medicines or herb-based remedies. Among all the efforts, accelerating the clearance of blood alcohol is a common strategy $[7,8]$.

Elaeagnus conferta Roxb is an edible herb found in Vietnam, Malaysia, India and South China. Its roots, leaves and fruits have been used in traditional Tibetan, Mongolian and Uygur medicine for the treatment of indigestion [9]. The native people in Yunnan province (South China) have been using its dried fruits to relief the aftereffects of alcohol for hundreds of years. But the effect of $E$. conferta Roxb dried fruit on alcohol metabolism has not been studied.

In the present work, the effects of $E$. conferta Roxb dried fruit powder (ECR) on blood alcohol clearance and on hepatic alcohol dehydrogenase (ADH) and aldehyde dehydrogenase (ALDH) activities were tested in acute alcohol-treated mice.

\section{EXPERIMENTAL}

\section{Plant materials}

The fruits of $E$. conferta Roxb (ECR) were provided by Xishuangbanna Yulin Pharmaceutical Co., Ltd., Yunnan, China. The plant was authenticated by Dr. Hubiao Chen (Health Science Center, Peking University, Beijing, China). A voucher specimen (no. YNG200604) was deposited in the Herbarium of Medical Plant, Beijing Institute of Technology, Beijing, China. The fresh fruits were dried in an oven at $80{ }^{\circ} \mathrm{C}$ for 4 days, ground into powder and suspended in $0.5 \%$ sodium carboxymethyl cellulose (CMC$\mathrm{Na}$.

\section{Chemicals and reagents}

$\beta$-nicotinamide adenine dinucleotide (NAD), 4-methylpyrazole, sodium deoxycholate and sodium pyrophosphate were purchased from Sigma (Beijing, China). Hongxing liquor (65 $\% \mathrm{v} / \mathrm{v}$ ethanol) was purchased from Hongxing Distillery (Beijing, China). Other chemicals were of analytical grade.

\section{Animal study}

The study was carried out according to the "Principles of Laboratory Animal Care" [10] and approved by the Institutional Animal Ethics Committee (reg. no. 200512/BITAEC).

A total of 240 Kunming mice were randomly divided into 20 groups with 12 mice in each group. The 20 groups were randomly subdivided into 5 supergroups with 4 groups per supergroup, namely normal control, negative control, and ECR-L, $M$, and $H$ supergroups. The normal control supergroup was given $0.2 \mathrm{~mL}$ of $0.5 \%$ sodium carboxymethyl cellulose (CMC-Na) solution only. Other supergroups were given Hongxing liquor (containing $65 \% \mathrm{v} / \mathrm{v}$ ethanol at a dose of $1.5 \mathrm{~mL} / \mathrm{kg}$, p.o.) to induce acute alcohol intoxication. Thirty minutes prior to alcohol administration, the negative control and the normal control supergroups were given $0.2 \mathrm{~mL}$ of $0.5 \%$ CMC-Na, while ECR-L, $\mathrm{M}$ and $\mathrm{H}$ supergroups were treated with different doses of ECR. The time interval between alcohol administration and onset of unconsciousness of each animal (referred to as 'resistance time') as well as the period during which animals remained unconscious (referred to as 'unconscious time') were noted. The unconscious state of the animals was determined by the loss of upright reflection. 
At $0.5,1,2$ and $4 \mathrm{~h}$ after alcohol administration, one out of the four groups in each supergroup was selected for blood sampling $(0.5 \mathrm{~mL})$ from the posterior orbital venous plexus. Blood ethanol concentration was measured by gas chromatograph according to the method of Steenaart et al [11].

\section{Enzyme activity assay}

To determine hepatic ADH and ALDH activities, 60 Kunming mice were treated as described above and sacrificed at different times after alcohol administration. A piece of liver tissue was taken from each animal. Hepatic ADH activity was evaluated according to Keung et al [12], while hepatic ALDH activity was determined using the method of Lindahl and Evces [13]. Briefly, the liver tissues were weighed and homogenized at a $1: 10$ ratio $(\mathrm{w} / \mathrm{v})$ at $4{ }^{\circ} \mathrm{C}$ in $0.1 \mathrm{M}$ Tris- $\mathrm{HCl}$ (pH7.0) containing $1 \mathrm{mM}$ dithiothreitol and 0.1 $\mathrm{mM} \mathrm{ZnCl}$. After centrifugation for $40 \mathrm{~min}$ at $31,000 \times \mathrm{g}$ at $4{ }^{\circ} \mathrm{C}$, the supernatants were removed for enzyme activity assays. The hepatic $A D H$ and ALDH activities were determined by monitoring the rate of $\mathrm{NADH}$ oxidation in the presence of acetaldehyde in cuvettes maintained at $25{ }^{\circ} \mathrm{C}$. NADH oxidation was recorded by a UV2550 spectrophotometer (Shimadzu, Japan) at 340 $\mathrm{nm}$.

\section{Statistical analysis}

The results obtained were expressed as mean \pm standard deviation (SD). Statistical significance was determined by one-way ANOVA followed by post-hoc Tukey test using SPSS 11.0 software. A value of $p<$ 0.05 was considered statistically significant.

\section{RESULTS}

\section{The nutrition profile of $E$. Conferta Roxb}

Table 1 lists the contents of some essential nutrients in the fruit of $E$. Conferta Roxb. The data were acquired by Beijing Center for Physical and Chemical Analysis, Beijing, China. The $E$. conferta roxb fruit is rich in $\mathrm{Ca}$, $\mathrm{Fe}, \mathrm{Mn}$ and $\mathrm{P}$. These minerals are necessary for good health, implying a favorable effect of this fruit on human health. The ratio of $\mathrm{K} / \mathrm{Na}$ is also high in E. conferta roxb fruit; this is good for the cardiovascular system [14]. The fruit contains as high as $7.339 \mathrm{~g}$ protein $/ 100 \mathrm{~g}$ dry weight. Its amino acid profile, shown in Table 2, indicated that aspartic acid (Asp) is the most abundant amino acid. The contents of other four essential amino acids, threonine (Thr), tyrosine (Tyr), lysine (Lys) and cysteine (Cys), were also high.

\section{Effect of ECR on blood alcohol clearance}

Fig $1 \mathrm{~A}$ shows that pretreatment with 800 $\mathrm{mg} / \mathrm{kg}$ ECR prolonged the resistance time and shortened the unconsciousness time of the animals $(p<0.01)$. Blood alcohol level after alcohol administration was inhibited by ECR pretreatment $(800 \mathrm{mg} / \mathrm{kg})$. As Fig 1B shows, decrease in blood alcohol was significantly facilitated. Thus, pretreatment with ECR stimulated blood alcohol clearance.

\section{Effect of ECR on hepatic ADH and ALDH activities}

Although low concentration of alcohol stimulates the activity of hepatic $\mathrm{ADH}$, high concentration of alcohol inhibits it [15]. In this study, a high dose $(0.15 \mathrm{~mL} / 100 \mathrm{mg})$ of Hongxing liquor (containing $65 \%$ ethanol)

Table 1: The mineral content ( $\mathrm{mg} / \mathrm{kg}$ dry weight) of the dry fruit of $E$. Conferta Roxb

\begin{tabular}{llllllll}
\hline $\mathrm{K}$ & $\mathrm{Na}$ & $\mathrm{Ca}$ & $\mathrm{Mg}$ & $\mathrm{Mn}$ & $\mathrm{P}$ & $\mathrm{Fe}$ & $\mathrm{Vc}$ \\
7250 & 879 & 1090 & 846.4 & 56.4 & 1390 & 85.2 & 35.2 \\
\hline
\end{tabular}


Table 2: Amino acid profile of $E$. Conferta vxb. dry fruit

\begin{tabular}{lll}
\hline Amino acid & $\begin{array}{l}\text { Content } \\
\text { mg/100g DW }\end{array}$ & \% \\
\hline Ala & 476 & $6.49 \%$ \\
Asp & 2652 & $36.14 \%$ \\
Arg & -- & -- \\
Cys & 536 & $7.30 \%$ \\
Glu & 173 & $2.36 \%$ \\
Gly & 86 & $1.17 \%$ \\
His & 106 & $1.44 \%$ \\
Ile & 336 & $4.58 \%$ \\
Leu & -- & -- \\
Lys & 545 & $7.43 \%$ \\
Met & -- & - \\
Phe & 205 & $2.79 \%$ \\
Pro & 220 & $3.00 \%$ \\
Ser & -- & - \\
Thr & 984 & $13.41 \%$ \\
Tyr & 715 & $9.74 \%$ \\
Val & 90 & $1.23 \%$ \\
Total & 7339 & $100 \%$ \\
\hline DW $=$ dry weight; -- = not detected &
\end{tabular}

A



B

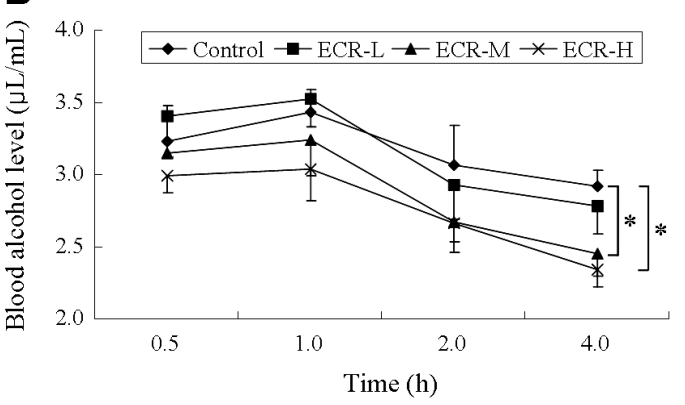

Fig 1: The effects of $E$. conferta roxb dry fruit powder (ECR) on alcohol intoxication resistance and unconsciousness (A); blood alcohol level (B) of mice following alcohol administration; * $p<0.05$ vs control. was used; this was much higher than the saturated alcohol concentration for hepatic ADH $(90 \mathrm{mg} / 100 \mathrm{~mL})$. Therefore, as Fig 2 shows, the activity of hepatic ADH was remarkably decreased after alcohol ingestion in our experiment. This in turn inhibited the activity of hepatic ALDH.

Pretreatment with ECR suppressed the inhibitory effect of high alcohol content on hepatic ADH activity (Fig 2A). Animals treated with ECR $(200,400$ and $800 \mathrm{mg} / \mathrm{kg})$ had significantly higher hepatic ADH activity at $0.5 \mathrm{~h}$ after alcohol administration compared with negative control (Fig 2A). This is in accord with the lower blood alcohol concentration and longer resistance time of the animals in these groups. Thereafter, ADH activity in the negative control group increased steadily but remained unchanged in ECR groups. However, ADH activity in the high dose ECR group was significantly higher than that in the negative control group at $4 \mathrm{~h}$ after alcohol administration.



B

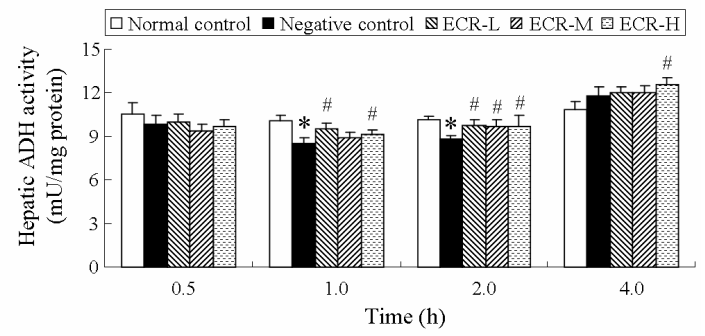

Fig 2: Effect of E. conferta roxb dry fruit powder (ECR) on the activity of hepatic alcohol dehydrogenase (ADH) (A) and aldehyde dehydrogenase $(\mathrm{ALDH})(\mathrm{B})$ in mice; ${ }^{*} p<0.05$ negative group vs normal control group; $" \#<0.05$ test group vs negative control group. 
Similarly, Fig 2B indicates that pretreatment with ECR suppressed the inhibitory effect of high alcohol concentration on hepatic ALDH activity. The inhibitory effect of alcohol intake on hepatic ALDH occurred about $0.5 \mathrm{~h}$ later than on $\mathrm{ADH}$. One hour after alcohol administration, hepatic ALDH activity in negative control group was lower compared with normal control. However, hepatic ALDH activity was not affected by alcohol in the groups pretreated with ECR. Four hours after alcohol ingestion, hepatic ALDH activity in the negative control group rose above that of normal control, while ALDH activity also increased in ECR groups and was higher than negative control (Fig 2B).

\section{DISCUSSION}

Alcohol abuse does a lot of harm to human health $[16,17]$. The metabolism of ethanol is mainly performed in liver by hepatic alcohol dehydrogenase $(\mathrm{ADH})$ and aldehyde dehydrogenase (ALDH) [18]. The accumulation of ethanol metabolites, especially acetaldehyde, in liver severely injured hepatic tissues, leading to alcoholic liver disease (ALD) which is one of the leading causes of death wordwide [19]. Therefore, accelerating the clearance of blood alcohol, thereby reducing the accumulation of its metabolites, helps to alleviate the toxic effect of alcohol in humans, especially on the liver. Agents that can enhance hepatic ADH and ALDH activities and stimulate alcohol clearance have the potential to decrease the harmful effects of alcohol abuse.

Several natural products have been shown the ability to stimulate blood alcohol clearance. For example, the Panax ginseng extract ( $3 \mathrm{~g} / 65 \mathrm{~kg}$ body weight) can decrease blood alcohol level by $35 \%$ at 40 min after the last drink in man [20]. The Antrodia camphorata powder can stimulate blood alcohol clearance in rats by increasing ALDH activity [21]. However, the active components in these medical sources have not been identified until now. Vitamin $C$ is also an important anti-alcohol agent. Chen et al reported that short-term and long-term pretreatment with ascorbic acid significantly enhanced the clearance of plasma alcohol [22].

E. conferta roxb is a nutritious fruit rich in inorganic nutritional minerals $(\mathrm{K}, \mathrm{Ca}, \mathrm{Mn}, \mathrm{P}$ and $\mathrm{Fe}$ ) and protein. Our results show that pretreatment with $E$. conferta roxb fruit powder (ECR) inhibited a rise in blood ethanol concentration after alcohol administration and also facilitated a decrease in alcohol level. The activities of hepatic ADH and ALDH in animals pretreated with ECR were higher than those for negative control. These results suggest that $E$. conferta roxb dry fruit powder promotes the activity of hepatic ADH and ALDH and thus accelerates clearance of blood alcohol and hence decrease its toxicity. Therefore, pretreatment with ECR may help to alleviate the harmful effect of high amount of alcohol in humans, especially the liver.

Although we report here the potential use of E. conferta roxb dry fruit for activating hepatic $\mathrm{ADH}$ and ALDH and accelerating blood alcohol clearance, the best remedy against the harmful effects of alcohol remains total abstinence or moderate drinking.

\section{CONCLUSION}

The results presented here suggest that pretreatment with $E$. conferta roxb dry fruit powder (ECR) enhances clearance of blood alcohol. It also preserves the activities of hepatic alcohol dehydrogenase (ADH) and aldehyde dehydrogenase (ALDH) following alcohol ingestion. Therefore, it possesses the potential to ameliorate the damage to human health that high alcohol intake often causes.

\section{CONFLICT OF INTEREST}

The authors declare no conflict of interest.

Trop J Pharm Res, December 2011;10 (6):765 


\section{REFERENCES}

1. Verrill C, Markham H, Templeton A, Carr NJ, Sheron N. Alcohol-related cirrhosis--early abstinence is a key factor in prognosis, even in the most severe cases. Addiction 2009; 104: 768-774.

2. Fernandez Checa JC, Bellentani S, Tiribelli $C$. Alcohol-induced liver disease: from molecular damage to treatment. Rev Med Chil 2002; 130: 681-690.

3. Suda K, Shiotsu H, Nakamura T, Akai J. Pancreatic fibrosis in patients with chronic alcohol abuse: correlation with alcoholic pancreatitis. $\mathrm{Am} \mathrm{J}$ Gastroenterol 1994; 89: 2060-2062.

4. Neiman J.Alcohol as a risk factor for brain damage: neurologic aspects. Alcohol Clin Exp Res 1998; 22: 346S-351S.

5. Taylor B, Rehm J, Gmel G. Moderate alcohol consumption and the gastrointestinal tract. Dig Dis 2005; 23: 170-176.

6. Sampson HW. Alcohol, osteoporosis, and bone regulating hormones. Alcohol Clin Exp Res 1997; 21: 400-403.

7. Lee FC, Ko JH, Park JK, Lee JS. Effects of Panax ginseng on blood alcohol clearance in man. Clin Exp Pharmacol Physiol 1987; 14: 543546 .

8. Lee SO, Lee HW, Lee IS, Im HG. The pharmacological potential of Sorbus commixta cortex on blood alcohol concentration and hepatic lipid peroxidation in acute alcoholtreated rats. J Pharm Pharmacol 2006; 58: 685-693.

9. Feng $W Y$, Wang $C T$, cHEN YG. Report on introduction of Elaeagnus conferta Roxb. Chin J Trop Crops 1986; 7: 139-146.

10. World Health Organization (WHO). Principles of laboratory animal care. Chronicle 1985; 39: 51-56

11. Steenaart NA, Clarke DW, Brien JF. Gas-liquid chromatographic analysis of ethanol and acetaldehyde in blood with minimal artifactual acetaldehyde formation. J Pharmacol Methods 1985; 14: 199-212.
12. Keung WM. Biochemical studies of a new class of alcohol dehydrogenase inhibitors from Radix puerariae. Alcohol Clin Exp Res 1993; 17: 1254-1260.

13. Lindahl $R$, Evces $S$. Comparative subcellular distribution of aldehyde dehydrogenase in rat, mouse and rabbit liver. Biochem Pharmacol 1984; 33: 3383-3389.

14. He FJ, MacGregor GA. Beneficial effects of potassium on human health. Physiol Plant 2008; 133: 725-735.

15. Vonwartb JP, Papenber J. Alcohol dehydrogenase in ethanol metabolism. Psychoso Med 1966; 28 : 405-413.

16. D'Costa G, Nazareth I, Naik D, Vaidya R, Levy G, Patel V, King M. Harmful alcohol use in Goa, India, and its associations with violence: a study in primary care. Alcohol Alcohol 2007; 42: 131-137.

17. Wright RM, McManaman JL, Repine JE. Alcoholinduced breast cancer: a proposed mechanism. Free Radic Biol Med 1999; 26: 348-354.

18. Yao CT, Liao CS, Yin SJ. Human hepatic alcohol and aldehyde dehydrogenases: genetic polymorphism and activities. Proc Natl Sci Counc Repub China B 1997; 21: 106-111.

19. Setshedi M, Wands JR, Monte SM. Acetaldehyde adducts in alcoholic liver disease. Oxid Med Cell Longev 2010; 3: 178-185.

20. Lee FC, Ko JH, Park JK, Lee JS. Effects of Panax ginseng on blood alcohol clearance in man. Clin Exp Pharmacol Physiol. 1987; 14: 543546.

21. Wu MT, Tzang BS, Chang YY, Chiu $C H$, Kang WY, Huang $\mathrm{CH}$, Chen YC. Effects of Antrodia camphorata on alcohol clearance and antifibrosis in livers of rats continuously fed alcohol. J Agric Food Chem. 2011; 59: 42484254.

22. Chen MF, Boyce HW Jr, Hsu JM. Effect of ascorbic acid on plasma alcohol clearance. J Am Coll Nutr. 1990; 9: 185-189. 